Article

\title{
Assistance or Resistance? Evaluating the Intersection of Automated Journalism and Journalistic Role Conceptions
}

\author{
Aljosha Karim Schapals ${ }^{1, *}$ and Colin Porlezza ${ }^{2}$ \\ ${ }^{1}$ Digital Media Research Centre, School of Communication, Queensland University of Technology, Brisbane, QLD 4059, \\ Australia; E-Mail: aljosha.schapals@qut.edu.au \\ 2 Department of Journalism, School of Arts and Social Sciences, University of London, London, EC1V OHB, UK; \\ E-Mail: colin.porlezza@city.ac.uk \\ * Corresponding author
}

Submitted: 23 March 2020 | Accepted: 10 June 2020 | Published: 10 July 2020

\begin{abstract}
Newsrooms are a social context in which numerous relationships exist and influence news work-be it with other journalists, the audience, and technology. As some of these relations change due to technological innovations, new hybrid contexts - technologies that are interwoven with newsroom values, routines, and socio-cultural experiences-can emerge. One key question is how journalists conceptualise and interact with such technologies, and to what degree they retain (creative) agency in the process. Therefore, this study evaluates the intersection of automated journalism and journalistic role conceptions. Using Hanitzsch's and Vos's circular model of journalistic roles (2017) and Deuze's understanding of journalism as an ideology (2005) as a theoretical framework, this study examines some of the discursive aspects of automated journalism by asking: To what extent are journalistic roles (a) challenged or (b) advanced as a result of automated journalism? Our findings more closely align with the latter, pointing to a strong sense of discursive maintenance of journalists' roles and their core skillset and thus suggesting a high degree of ideological continuity in the face of industrial disruption. It concludes with an agenda for future research and stresses that at times when journalism and automation intersect, the field would benefit from incorporating emerging conceptual frameworks such as human-machine communication.
\end{abstract}

\section{Keywords}

algorithmic journalism; automated journalism; computational journalism; journalism; news; newsroom; technology

Issue

This article is part of the issue "Algorithms and Journalism: Exploring (Re)Configurations" edited by Rodrigo Zamith (University of Massachusetts-Amherst, USA) and Mario Haim (University of Leipzig, Germany).

(C) 2020 by the authors; licensee Cogitatio (Lisbon, Portugal). This article is licensed under a Creative Commons Attribution 4.0 International License (CC BY).

\section{Introduction}

On 1 February 2019, The Guardian Australia published its first news story written by its in-house automated system, ReporterMate. This followed an upward trend observed in journalism since 2014: the rise of 'robojournalism,' narrative texts generated by computational tools allowing for the partial automation of the news writing process "with limited to no human intervention beyond the initial programming choices" (Carlson, 2015, p. 416) and deployed particularly for data-intensive beats. A prominent example is the Los Angeles Times's website "The Homicide Report," which includes elements of automated journalism to report on the latest crime news across the city (Young \& Hermida, 2015). Also in the United States, Forbes, The New York Times, The Atlanta Journal-Constitution and ProPublica are known to make use of, or at least experiment with, these types of innovation (Graefe, 2016; Hansen, Roca-Sales, Keegan, \& King, 2017). Elsewhere, examples include both the Berliner Morgenpost and the Handelsblatt newspapers in Germany (Dörr, 2016). Here in particular, a number of private companies have since established themselves as leaders in the field of automated text 
generation. One of them, Retresco, was awarded the United Nations' World Summit Award in 2017 for its use of artificial intelligence (AI) in the field of natural language generation (NLG). While much has been made of its potential of freeing up journalists for more sophisticated workplace tasks (Graefe, 2016), the introduction of new technologies in journalism has historically been met with a great deal of resistance on behalf of those most affected by them-namely, journalists themselves (Thurman, Dörr, \& Kunert, 2017). If the words of Harvard Business School Professor Shoshana Zuboff (1988)-“everything that can be automated will be automated" - are to be believed, what of the social implications for journalists and how they conceive of their roles as automation becomes an integral part of contemporary newsrooms?

A core question emanating from this consideration is the extent to which journalists retain (creative) agency in relation to such new technology, which is gaining agency in the form of Al (Jones, 2019). According to Guzman and Lewis (2020), "much has yet to be learned regarding how people conceptualize and interact with these more advanced technologies within the context of their daily lives" (p. 8). In this regard, this study's main goal is to increase our understanding of how journalists respond to algorithmically led automation processes-and automated journalism in particular-in the newsroom, as well as how they articulate journalism's core ideals as a result of it. Building on Hanitzsch's and Vos's (2017) circular model of journalistic roles and their discursive construction as a theoretical framework, as well as 10 semi-structured interviews with editors and journalists across several German media organisations, this study extends our understanding of how journalistic roles are either (a) challenged or (b) advanced as a result of algorithmically-driven datafication. More specifically, do journalists feel that their performance is enabled or constrained by automated journalism? Thus far, much of the discourse on automated journalism is characterised by a somewhat Manichean stance, suggesting a zero-sum dichotomy of enabler versus constraint. Such a view, however, omits that "new technologies have always been met with overtly optimistic or pessimistic scenarios arguing that the new development will change media content for better or for worse. Automated content creation is no exception" (van Dalen, 2012, p. 654). The rise of automated journalism, therefore, heeds the call for a better understanding of how journalists interact with technology in the context of contemporary newswork ( $\mathrm{Wu}$, Tandoc \& Salmon, 2019).

As such, we suggest that the introduction of automated journalism into contemporary newsrooms forces a rethink of how journalists conceive of and perceive their roles in light of algorithmically driven datafication. After all, newsrooms are a social arena in which numerous relationships exist and influence newsworkamongst journalists, the audience, and technology in and of itself (Lewis \& Westlund, 2015). However, thanks to technological innovations such as automated journalism, these relationships find themselves in a state of flux, leading to hybrid arenas in which novel technologies are interwoven within long-held newsroom values and routines. Building on the work by Wu et al. (2019) on the social implications of newsroom automation as it becomes part of the social arena the newsroom constitutes, we thus ask: Do algorithmically led automation processes in the newsroom lead to a reconfiguration of journalistic role conceptions? In considering these social implications as a guiding logic throughout our study, we also imply that much of the existing research on the intersection of algorithms and journalism emphasises the tangible, technical shifts occurring - but it (somewhat inadvertently) omits the cultural lens through which these shifts can be observed. As such, our focus moves away from the object (the technology itself) and instead considers the subject(s) (the journalists) and their associated roles, values and conceptions.

We do so by revisiting Hanitzsch's and Vos's (2017) theoretical framework on journalistic roles and their discursive construction and Deuze's (2005) notion of journalism as a professional ideology by evaluating its intersection with automated journalism. Following this, we add to empirical knowledge by presenting in-depth interviews with editors and journalists across major German news organisations to shine light on the discursive aspects of automated journalism as well as assessing whether their journalistic 'performance' is enabled or constrained as a result of automation. Our findings reveal that journalists see automation as supplementary rather than expendable to their work; automated journalism is perceived as complimentary to rather than competing with their existing skillset (Neuberger \& Nuernbergk, 2010). Their narratives point to a strong sense of discursive maintenance of journalists' roles and their core skillset, thus suggesting a high degree of ideological continuity (Deuze, 2005) in terms of their professional orientation, even if they face industrial disruption.

\section{Literature Review: Automated Journalism, Journalistic Roles, and Professional Ideology}

Given the relative novelty of the phenomenon of automated journalism, academic research on the subject so far remains limited. However, a small number of previous studies have made first forays in illuminating the issue further, ranging from experimental studies in which journalists were able to gain first-hand experience with the software (Thurman et al., 2017) to studies in which key journalistic staff were asked about their uses of and experiences with the technology. These include Bucher's (2017) study on how the computational is articulated in the newsroom. Drawing on in-depth interviews with Swedish journalists, she finds that the integration of computational processes in the journalists' newswork is something staff think about rather than think with. Computational processes had yet to be fully 
implemented at the time, and the use of software did not replace human journalists but rather supplemented their work. The viability of traditional journalistic labour was thus maintained: Indeed, she finds that "claims about the inferiority of the machine...need to be understood as a discursive strategy used to maintain the distinctiveness and value of journalistic professionalism" (p. 931). This is congruent with previous studies which confirm the viability of traditional journalistic values even when faced with automation (Karlsen \& Stavelin, 2014). For the technology to genuinely fulfil its potential in Norwegian newsrooms, "craftsmen with knowledge to build, wield and aim the technology are needed" (p. 45). Retrospective analyses of how automation was gradually introduced into the newsroom over decades further suggest the extent to which journalists mitigate the introduction of increased automation in the newsroom (Linden, 2017). Because automated journalism still is a somewhat small domain to this date-and largely limited to 'elite' and resourceful news organizationssuch analyses reject the notion of a possible replaceability of humans by the machine. Instead, journalism understood as an ideology (Deuze, 2005), conveying how journalists attribute their work with meaning, will likely continue to be a mitigating factor to counter automation in the newsroom.

Pioneering research into the phenomenon of automated journalism was conducted by Graefe (2016) in his Guide to Automated Journalism. The technology, he argues, offers unprecedented opportunities for producing a large number of articles in different languages in an extremely short space of time, allowing managerial staff to lower production costs while at the same time increasing profit margins. Equally, however, fears are rife that an increase in available articles could lead to information overload, resulting in a lack of orientation in an already 'noisy' digital news environment: "An increasing quantity of available news will further increase people's burden to find news that is most relevant to them" (Graefe, Haim, Haarmann, \& Brosius, 2016, p. 12). Concerns also revolve around the fact that automation could lead to the gradual disappearance of newsroom jobs that are characterised by data intensity, such as weather reports and financial news coverage (Carlson, 2015). Furthermore, algorithms cannot fill the gap that would be left by human journalists should the technology indeed lead to a gradual elimination of such rank-and-file roles: Algorithms cannot interrogate data or even establish causality and are therefore "limited in their ability to observe society and to fulfil journalistic tasks, such as orientation and public opinion formation" (Graefe et al., 2016, p. 6). Or, in other words: "Algorithms can provide accounts of what is happening, but they cannot explain why things are happening" (Haim \& Graefe, 2017, p. 1056; emphasis in original). Graefe thus advises journalists to focus their attention on skills that give them a competitive advantage over increased automation, that is, their ability to create in-depth, investigative journalism that would still re- quire journalists to ask probing questions and to apply a healthy amount of skepticism.

Previous studies range from experimental studies of readers' perceptions of automated journalism (Haim \& Graefe, 2017) to workshops allowing journalists to experiment with the software themselves (Thurman et al., 2017) or as design partners for Al-based tools in journalism (Gutierrez-Lopez et al., 2019). Some of these involve in-depth interviews with practitioners in the field, a widely used method "to gain insights into the individual experiences, attitudes and views of a select group of professionals working in the area of journalism" (Hermida \& Young, 2017, p. 173). However, far less research has thus far uncovered how journalists themselves perceive the phenomenon of automated journalism and its impact in the workplace. This, however, is essential in order to better comprehend how the role of journalism is not just understood as a profession, but as an ideology, giving insights into how journalists attribute their labour with meaning (Deuze, 2005) and navigate in an environment characterised by frequent innovations, illuminating, not least, "how these technologies reproduce, embody or alter norms of professional ideology" (Young \& Hermida, 2015 , p. 384). It further sheds light on what journalists understand their own role to be and the ways in which this understanding gives "meaning to their work...to justify and emphasize the importance of their work to themselves and others" (Hanitzsch \& Vos, 2017, p. 115). This is a necessary notion to revisit in a media environment best characterised by significant disruption in an increasingly dense, complex, hybrid, multi-channel, interactive and participatory information environment.

According to Hanitzsch's and Vos's circular model of journalistic roles and their discursive constitution, we consider their proposed roles in light of automation in the newsroom. Four roles have been suggested: normative ideas (what journalists should do and what society expects of them); cognitive orientations (what journalists want to do, and how this idealised scenario corresponds to the normative roles expected of them); professional practice (what journalists actually do and how they execute their work, possibly also in light of real-life workplace constraints); and their narrated performance (what journalists say they should do, through a process of internal negotiations). Adopting this framework is relevant in the sense that "the discourse of journalistic roles is the central arena where journalistic identity is reproduced and contested; it is the site where actors struggle over the preservation or transformation of journalism's identity" (Hanitzsch \& Vos, 2017, p. 129). Precisely how their identity is shaped by automation novelties has received little attention so far, yet, in light of such transformative change, conceptualising the human-machine relationship through the prism of journalists' discursive construction of their identity addresses an important gap evident in existing scholarship. It is precisely for this reason that in-depth interviews were particularly well-suited as a methodological approach for this study, as they help 
us "understand the social actor's experience, knowledge and worldviews" (Lindlof \& Taylor, 2010, p. 173).

In addition, our work also considers how journalists negotiate their professional ideology (Deuze, 2005) in the face of automation, specifically how journalists constitute their work as meaningful to themselves and others in a discursive construction (Hanitzsch \& Vos, 2017). According to Deuze (2005), these include five ideal-typical values: public service (journalists as disseminators of information and 'watchdogs' over society); objectivity (journalists adopting an impartial and neutral stance in their reporting); autonomy (journalists as free and independent actors); immediacy (journalists' instantaneous working practices); and ethics (journalists' adherence to a code of conduct). It is worth pointing out that these two theoretical concepts are herein invoked for their general focus on how journalists articulate their professional purpose, rather than for their elaboration on specific roles and values, and automation's relationship to those. Still, studying these normative ideals indepth allowed us to understand "how journalists from all walks of their professional life negotiate the core values [through which] one can see the occupational ideology of journalism at work" (p. 458). But are these core values subject to change with respect to the rise of human-machine communication? Or do we, perhaps, see a degree of ideological continuation in the face of industrial disruption? In revisiting his earlier work in light of profound industry transformations, Deuze (2019) suggests the latter, namely:

A commitment to the ideology of journalism [that] remains firmly in place.....Their loyalty to journalism as an ideal remained intact.....Journalism [as an ideology] remains the same, yet the conditions under which it is practised have not only changed considerably, they are in permanent flux. (p. 2)

As such, this study is centred on the future of journalistic labour (Carlson, 2015): We consider both the extent to which journalistic roles and the discursive constitution of their identity (Hanitzsch \& Vos, 2017) as well as journalists' professional ideology (Deuze, 2005, 2019) are (a) challenged or (b) advanced as a result of introducing a-potentially disruptive-technology in the newsroom, particularly in light of journalists' expressed sense of autonomy. Are they still the sole holders of said autonomy at a time when a new entrant-technology itselfbecomes embedded into the social fabric of the newsroom? While much has been made of its utility to assist editorial newswork-be it its data-scraping prowess or at-scale production capacity-existing research highlights the exclusivity of human agency in journalistic articulations about their professional identity. In clearly demarcating human from algorithmic storytelling, journalists stressed elements such as creativity and critical thinking to discursively maintain the centrality of their professional autonomy (Carlson, 2015). As such, "reconsiderations of what makes human-produced news unique suggest that journalistic authority derives from something more than delivering objective information about the world; it thrives on dissecting the drama of public life and the emotionality of quality news writing" (Carlson, 2015, p. 428). The fact that algorithmic judgement in newsrooms has now been institutionalized (Thurman, 2019) "compels greater sensitivity to the distinctiveness of professional journalistic judgment and algorithmic decision-making. Most expressly, journalists need to forge new arguments for their cultural authority based on their active suitability to render thoughtful judgments" (Carlson, 2018, p. 1768).

In sum, we suggest that the introduction of automated journalism branches out into three interrelated consequences: (1) the increasing commodification of journalism (as a result of automated articles being produced at-scale); (2) its enhanced approximation to resemble human work (as the technology continues to improve); and (3) its gradual normalisation (as use of and acceptance for it start to take hold). This, in turn, has a direct and tangible impact on said autonomy, which may be compromised and thus stands in stark contrast to journalists "espousing their irreplaceability" (Carlson, 2015, p. 425). In-depth interviews with professionals in the field allowed us to evaluate the intersection of automated journalism and journalists' long-held professional ideology accordingly.

\section{Method}

As mentioned, the still relatively novel phenomenon of automated journalism finds particular applicability in special interest outlets covering beats prone to automation. In Germany, for example, the local newspaper Berliner Morgenpost and the Handelsblatt have piloted the software, particularly for financial news and stock exchange reports. That said, however, it is important to note that many journalistic clients of NLG service providers operate under strict contractual nondisclosure agreements, possibly a result of not necessarily wanting to be associated with a technical novelty that, at least in some parts of the industry, is still looked at with a hint of skepticism (Graefe, 2016). As a result, with the exception of Dörr's (2016) study, which offers an overview of service providers of NLG across special interest journalistic clients, reliable data on either existing usage or possible future implementation of the software across German media organisations are virtually non-existent. Given the technology's widely predicted uptake in the years to come, and Graefe's (2016) outlook that "the quality of automated news will likely continue to improve, both in terms of readability and the ability to generate insights that go beyond the simple recitation of facts" (p. 40), this study deliberately set out to fill the gap left by Dörr's (2016) study and its focus on special interest outlets. Instead, it focussed on staff working for major German news organisations who 
might not (yet) make use of the technology in the actual production of journalistic work, but whose organisations have in the past deployed algorithms to assist editorial newswork in 'big data' projects. With this rationale in mind, four news organisations were considered to be particularly relevant to this sample: Spiegel Online, known for its automated rating of a soccer player's performance in its Spielerindex application (Montazeri \& Kolbinger, 2017); Süddeutsche Zeitung, known for its pioneering use of algorithms to sift through the Panama Papers files; Frankfurter Allgemeine Zeitung, known for its automated topic pages powered by Retresco (2017); and Zeit Online with its Street Names project, an interactive tool which looks for patterns in the distribution of street names across Germany. The latter project relied on data gathered by service provider Geofabrik and was nominated for the prestigious Grimme Online Award in 2018, an annual prize which honours particularly innovative journalistic work in Germany (Zeit Online, 2018). Another award-winning case in Germany is the Feinstaubradar (fine dust radar) project by the Stuttgarter Zeitung, which cooperates with locally based AX Semantics to produce daily, automated reports on the city's high concentration of fine dust in the atmosphere (Stuttgarter Zeitung, 2018). Unfortunately, however, interviews with newsroom staff working at the Stuttgarter Zeitung could not be realised due to the submission deadline of this paper. In addition to the outlets mentioned in Dörr's (2016) study, these are prominent examples which have attracted ample media coverage in Germany thanks to their inventive use of algorithms to assist contemporary editorial newswork.

In a next step, potential interviewees who could be questioned on perceptions of and reactions to the phenomenon of automated journalism as well as its use in relation to journalism's professional ideology had to be identified. To do so, the researchers subscribed to the Cision Media Database, which hosts worldwide contact details of journalists working for different media organisations across the globe. Two different groups of newsroom staff were identified as being particularly wellsuited to this study: first, journalists working in domains such as business and finance, weather and sports cover- age more generally; second, newsroom staff with some editorial oversight were selected from the database, so as to accumulate rich insights from various hierarchical levels in the newsroom including rank-and-file staff as well as senior management. The contact details of newsroom staff who best fitted that description were then exported from the database. 73 editors and journalists were contacted by email in the first instance, and, if necessary, a second time in a follow-up email. These contact requests resulted in a total of $n=10$ positive replies (response rate: $13.7 \%$ ). All interviews were conducted in January 2018 via telephone or Skype, with the exception of one interview whose responses were provided via email. Despite the less favourable, asynchronous properties of an email interview - which is void of social interaction and does not allow the interviewer to ask immediate follow-up questions-in this particular instance, they still yielded rich and helpful insights.

With each interview lasting an average of 30 minutes, responses were subsequently transcribed verbatim and translated from German into English. Participants were assured that interviews would be conducted on the basis of anonymity, that is, instead of revealing their identity, respondents were assigned alphabetical codes as per Table 1. Following on from the transcription, the collected interview data was analysed qualitatively to uncover emerging narrative patterns, allowing the researcher to "draw together the data collected and structure them in such a way as to make ready for analysis" (Wilkinson \& Birmingham, 2003, p. 63). The journalists' narratives were written up, compared with each other and clustered into themes so as to "weave in a narrative...interpolated with illustrative quotes" (Gillham, 2000, p. 74). Overall, the findings point to the ways in which journalists' roles were either (a) challenged or (b) advanced as a result of automation novelties, and ways in which these impact on possible reconsiderations of their professional ideology.

Following a first round of interviews with newsroom staff working for the four selected organisations, two supplementary interviews with a reporter and a freelance journalist known as experts in the field were conducted which helped substantiate the results emanating from

Table 1. Sample of interviewees including media outlet and position held.

\begin{tabular}{lll}
\hline Code & Media Outlet & Position \\
\hline A & Spiegel Online & Data Journalist \\
B & Netzpolitik & Reporter \\
C & Zeit Online & Editor in executive position \\
D & Süddeutsche Zeitung & Editor in executive position \\
E & Süddeutsche Zeitung & Editor in executive position \\
F & Freelance & Data Journalist \\
G & Süddeutsche Zeitung & Editor in executive position \\
H & Frankfurter Allgemeine Zeitung & Business Journalist \\
I & Frankfurter Allgemeine Zeitung & Sports Journalist \\
J & Süddeutsche Zeitung & Data Journalist \\
\hline
\end{tabular}


the first round of conversations. Our core research question was:

RQ: To what extent are journalistic roles (a) challenged or (b) advanced as a result of automated journalism?

\section{Findings}

The purpose of this study was to aid our understanding of how journalistic roles are either (a) challenged or (b) advanced as a result of algorithmically driven datafication. More specifically, do journalists feel that their performance is enabled or constrained by automated journalism? We hypothesised that-given its ability to lower production costs while at the same time increase profit margins-editorial staff in managerial positions would be positive towards its increasing introduction, while less senior reporters would voice concerns in relation to possible replacement fears (Bucher, 2017) by the technology, particularly in the years to come as it is expected to improve its various affordances (Graefe, 2016).

\subsection{Man versus Machine?}

The results do not support this hypothesis. With the exception of one journalist (I), interviewees overall dismissed the idea that professional roles currently performed by human journalists would need to give way to technology in the future. Crucially, their responses give credence to what was previously described as "journalism as an ideology" (Deuze, 2005), that is, how journalists give meaning to and legitimise their professional roles. Indeed, respondents were eager to defend their roles in the face of automation-roles which, to their mind, would exclusively align with the capabilities of human journalists: indeed, it was especially striking how frequently interviewees used terms such as "creativity" $(I, C, H)$, "context" (A, D) and "uniqueness" $(I, E)$ in their responses.

Their overall perception and understanding of journalism predominantly manifested itself as an art or a craft rather than "some manual task on an assembly belt" (H). That special craft could, according to the interviewees, best be described by linguistic eloquence, stylistic nuance and a general need to not merely convey facts objectively, but to contextualise them, that is, to take readers by the hand and help understand the deeper meanings, possible consequences and wider (societal) significance of the factual information they are consuming. They also stressed the need for a human editor to double-check and to validate accounts of sports or financial news coverage-both beats particularly prone to increasing automation in the future. As one editor for the Süddeutsche Zeitung remarked:

If there is even just a grain of assessment or evaluation in the text, then I do believe it is absolutely crucial for a human editor to thoroughly double-check
that....[But] I am not worried that computers will replace human editors in the future-because I do not believe that that sort of assessment or evaluation can possibly be implemented in automatically-generated content just yet. (D)

Their colleague at Spiegel Online concurred: "I simply cannot see this [automated journalism] to go beyond purely descriptive coverage. As soon as it comes to interpreting events and contextualising them, I do not believe that algorithms could ever possibly fulfil that $\operatorname{task}^{\prime \prime}(A)$. Beyond the aforementioned linguistic eloquence and stylistic nuance, interviewees further believed in the narrative function of journalism, which is to pursue a red line that provides background information and adds context. In this, they see an added value function that purely factbased re-narration of events would not be able to accomplish. In the words of a data journalist at the Süddeutsche Zeitung:

Generally, I am very positive about this [automated journalism] [and] I am not worried about being replaced by it [the software]. You will always have to speak to protagonists and experts, and there will always need to be someone who binds it all together and puts it into a narrative. (J)

This was mirrored by a colleague:

Journalism is far too much a creative industry for there to be people who would only want to consume fact-based news....I'm quite optimistic when it comes to technology. Because technology brings us more than it hurts us. And the same applies to automated journalism. (H)

\subsection{Supplementary or Expendable?}

Crucially, not only was there general optimism towards technological innovation, but there was broad agreement among both senior editors and reporters that their work would not be replaced by automated journalism but rather be supplemented by it-a finding which aligns with previous research on the issue (Bucher, 2017). Respondents were upbeat about the various opportunities automated journalism could bring to the newsroom-which was, first and foremost, an ability to free them from "annoying duties" $(A)$ and thereby allow them to devote themselves to more analytically rigorous tasks. As one journalist put it:

I definitely see a chance in this [automated journalism]. Because it won't replace the work of editors but supplement it; it can complement it even....And so, in the future, editors will be freed from such [basic] work, meaning that they'll have more time for deeper investigations that algorithms themselves cannot deliver. (A) 
The data journalist working for Zeit Online was of the same opinion: he, too, believed that the basic tasks of rank-and-file journalists could give way to increasing automation without reporters having to be overly concerned about being 'replaced' by the machine. To his mind, the journalism industry would transform in a way that would allow reporters to pursue "more exciting narratives" (C, J) while somewhat simplistic factbased reporting would be performed by algorithms. He explained that:

There are no alarm bells ringing for me that this [automated journalism] would make human editors replaceable. I would rather think that if robots complete very basic bread-and-butter tasks that resources would be freed up in the newsroom.... don't see the whole industry in danger just because two editors leave because robots do that sort of thing now. (C)

This argument was supported across the board, with automated journalism generally seen as a "positive development" (F). Notwithstanding some of the economic imperatives journalism as an industry faces, which may constrain the extent to which journalists are able to enact some their roles (Hanitzsch \& Vos, 2017), such narration underscores the ideal of autonomy journalists pursue, which places them as free and independent actors in their newswork (Deuze, 2005)-an ideal they see as remaining intact in the space of automated journalism. A notable exception was the sports journalist working at the Frankfurter Allgemeine Zeitung, who regarded this as a somewhat naïve fallacy pursued by those who are generally favourable towards technological innovation. He said: "I tend to be rather worried about it. I don't know if this whole claim, that it would be free up resources for in-depth investigations, isn't perhaps somewhat self-deceiving" (I).

\subsection{Professional Ideology-Revisited?}

As mentioned before, previous studies indicated that computational processes in journalism are something journalists passively think about rather than actively think with, thereby re-affirming, once again, the supplementary rather than the expendable function of its specific subset of automated journalism (Bucher, 2017). Indeed, the interviewees' reflections on automated journalism spurred on reflections about the deeper meaning journalists attribute their work with, exposing, inter alia, the normative and ideologically driven sensemaking mechanisms described earlier (Deuze, 2005). These were, as it happens, diametrically opposed to the capabilities of automated journalism. One interviewee went as far as to suggest that "automated journalism misses the basic journalistic function...to contextualise information properly" (E). He continued, "to simply convey the facts is not attractive for the reader...[But] what will bring them to our product is how these facts are con- textualised and how they are presented in context within a written format."

In stressing the exclusivity of the journalism profession, his colleague at Zeit Online concurred: "Journalism has to be unique, always. Pure information that is merely conveyed as fact is not exactly spectacular" (C). His colleague, the sports journalist at Frankfurter Allgemeine Zeitung, went a step further and saw little value in automated journalism altogether. He stressed his preference towards content produced by humans-for the exact same reason of it being a "unique" piece of work "crafted" by an individual. In his words, "I want something that is uniquely created by journalists. I don't even need the most objective, factual or data-heavy content. The reason I like consuming journalism...is because I think these are people who know their stuff" (I). The importance of human intervention in that process was also evident in that "the whole point of journalism is that human beings observe what is happening in the world out there and how they therefore describe, assess and contextualize that" (I).

\subsection{What Is Journalism?}

It is because journalists did not feel threatened by such technological innovation and were equally unconcerned about possible future replacement by the machine that interviewees saw their journalistic 'mission' not just in the need to report the data, but to extract its deeper meaning and consequences (C, D) as well as an ability to approach and interact with informants to uncover newsworthy clues for further investigation $(A, H)$. In other words, they urged fellow journalists to focus on skills that human journalists embody (Thurman et al., 2017). One editor at Süddeutsche Zeitung, for example, was convinced that what was increasingly required was "that special journalistic impulse" which included "curiosity about what the story behind the data is...[Otherwise] it is hard to convey your message which will make the story interesting and readable in the first place" (D). A colleague agreed with this sentiment when he stated that "as a journalist, you should be able to understand what sort of information can be hidden away in data and what patterns you should keep an eye out for" (C).

In addition, interviewees were eager to stress a need for the remnants of traditional research skills and journalistic practice, that is, to meet informants, speak to them and to experience events at the scene through one's own lens. Despite his data-intensive professional background, a data journalist at Spiegel Online even prioritised such traditional research skills over the data scraping capabilities a journalist in his field should possess-capabilities which would provide nothing more than some degree of 'added value.' To his mind, "with data research, what follows is always traditional research. I need to speak to people and let those involved have a say. That's the first bit. And what comes on top of that are technical skills" (A). One interviewee put it even more bluntly 
when he said that, "without the willingness to meet new people and to approach them directly, [and] without curiosity, nothing is possible" $(\mathrm{H})$. Conceiving of their roles in this manner underscores journalists' normative and internalised cognitive role orientations in contributing to the proper workings of democracy (Hanitzsch \& Vos, 2017). This found particular expression in the public service role (Deuze, 2005) journalists attribute their work with, which includes a unity of purpose to act as servants for the public and as 'watchdogs' over society. Given the journalists' expressed belief of freed-up resources to devote to in-depth investigations in the space of automated journalism, this ideal may not only remain intact, but could in fact be strengthened.

\subsection{Assistance or Resistance?}

Contrary to initial hypotheses, the interviewees' responses indicated a general enthusiasm and positivity towards automated journalism irrespective of professional hierarchy, primarily on the grounds that the technology could free up resources to allow for more in-depth investigations requiring the skills of human journalists. Rather than replacing their work, journalists were upbeat about the supplementary toolkit they would receive as a result of increasing automation in the newsroom. One journalist stressed his expectation for strengthened future collaborations between reporters and technical staff (F), as was the case in the much-referenced Panama Papers investigation revealed by the Süddeutsche Zeitung.

One example of how automation can aid the work of rank-and-file journalists was mentioned by a data journalist at Spiegel Online. Referencing their coverage of soccer matches, he explained their collaboration with sports analytics company Opta, which the provides the newsroom with large data sets after each match. The data contains a host of parameters which would then be paired with their in-house technology SPIX (Spielerindex), which helps rate each player based on their performance. This would be passed on the reporter who would then "put text around it" (A). He further stressed the general suitability of sports coverage to be aided by computational processes, "just because so much data is available" and was expecting such an uptake in the future.

His colleague at Zeit Online saw automation to be particularly applicable to automatic alerts in the future, that is, notifying journalists of sudden events, such as earthquakes, via push alerts on their mobile devices or email notifications on their desktop computers (C). Another interviewee expected automated journalism to be applicable to smaller, local newspapers, while he was expecting larger organisations to experiment with personalisation of content rather than full automation (B).

\section{Conclusion}

The interviewees' various accounts provide us with insights into whether media practitioners in German news- rooms feel that their roles are either (a) challenged or (b) advanced as a result of automated journalism. Contrary to somewhat inflated man-versus-machine narratives suggesting the gradual replaceability of human journalists by 'robo-reporters,' newsroom staff sensed that the technology's opportunities would indeed advance their roles. As such, they rejected the idea of feeling threatened by technological innovation-and with the exception of one sports journalist, this was the case across the board, irrespective of the level of hierarchy the individual had attained in the newsroom. In fact, quite the opposite was the case: Both editors and journalists were upbeat about the opportunities automated journalism could bring with itself-first and foremost, its ability to free themselves from the daily grind of purely factual reporting and to instead devote their resources to profound, in-depth investigations requiring the skills that human journalists embody. As a result, this study is in agreement with previous research on how the computational is shaping journalistic practice and broader role understandings: In this context, interviewees felt that automated journalism would supplement rather than replace their work (Bucher, 2017), leading them to see innovative approaches to the journalism domain as complementary rather than competing (Neuberger \& Nuernbergk, 2010). While being generally positive towards technological innovation, it was only in their own, human work that they genuinely sensed a degree of 'added value.' This found expression in journalists' articulations of their profession as a creative process, used as discursive means to demarcate their human skillset from the affordances automation would bringnot just to the journalism domain, but in creative and artisanal industries as a whole (Linden, 2017). Interestingly, this finding also points to widespread shifts as evidenced in decades of newsroom ethnographies: Observations of the 1970s have indicated a level of conformity, institutionalism and rigidity to constrain journalistic creativity to the point where it was linked to assembly-line work (Gans, 1979; Tuchman, 1978)-a metaphor used by one of our own interviewees to differentiate his distinct professional practice. Remarkably though, an assembly-line perspective of newswork with its focus on increased efficiency is gaining traction as of late: Although being more flexible, adaptable, and scalable in the composition of its elements, so called structured and 'atomised' forms of journalism are becoming more common (Jones \& Jones, 2019).

Most strikingly, however, conversations about automated journalism have led journalists to rigorously defend their own work-or indeed, "craft," as many referred to it-in the face of automation. Through their narrated performance, a process of normalisation takes place, which in turn reinforces their normative roles (Hanitzsch \& Vos, 2017). Once again, it is worth bearing in mind that our study did not examine specific roles, but instead looked more generally at the articulation of these roles as a means of maintaining professional ideol- 
ogy. That said, reflections on what journalism is becoming as a result of digitisation has not only led journalists to preserve their normative, professional ideology: Indeed, it has led them to stress the normative foundations upon which traditional definitions of journalism are built. These included, but were not limited, to: journalism as a creative process; journalism as a uniquely individual craft; as well as the need to add background and context in order for recipients to contextualise information accordingly. They also referenced journalism's core ideals of public service and autonomy (Deuze, 2005) and continued to position themselves as authoritative actors in the space of automated journalism. Providing context, orientation and interpretation were referenced as (self-serving) means to suggest that journalistic authority far extends a dogged pursuit of factuality; in fact, the former were constructed as superior traits under which journalistic storytelling would genuinely thrive (Carlson, 2015). In contrasting these human capabilities with the affordances of the technology, one of the most telling accounts was voiced by one editor when he asked: "Can journalism even be automated to begin with? I wonder if that is not a contradiction in its own right" (E).

Such considerations provide fertile ground for future research. For example, does an expansion of automated journalism genuinely lead to an uptake of investigative reporting as a result of freed-up resources, as voiced by so many journalists? Or is a healthy dose of skepticism, such as expressed by one journalist who felt the idea was somewhat "self-deceiving" (I), perhaps more reflective of reality? Indeed, should we take journalists' assertions that their autonomy and value are aided and not undermined by automation at face value, or should we perhaps rather interpret these as somewhat self-serving rhetorical defences of their own, professional worth? Longitudinal studies would help to genuinely uncover this development over time, giving insights into whether the predicted, positive shift resulting from a gradual expansion of automated journalism is valid and, indeed, justified. Such research into the implementation of automated journalism over time would also help address this exploratory study's main limitations: first, its set-up as a pilot means that the findings are indicative; a larger research population would represent a wider cross-section of both editors and journalists alike and, as such, result in more generalizable patterns as the technology continues to be implemented in the newsroom. Second, our exclusive reliance on in-depth interviews needs to be addressed: The research interview as a form of metajournalistic discourse, which entails performative aspects of journalists defending their own value when taken-forgranted practices are suddenly contested, "spurs efforts to define appropriate practices while dispelling deviant or outsider actions" (Carlson, 2015, p. 352). As such, our approach has limited methodological scope as it is based on self-reported data, which has the potential to generate socially desirable responses, and, thus, skew onthe-ground realities. Third, while the composition of the sample deliberately sought to supplement Dörr's (2016) study by focusing on mainstream media, it means that this particular set of actors may suffer from certain structural influences or biases that may not apply in other contexts: Indeed, our interviewees may be more receptive to automation's role and more confident in their own autonomy due to the fact that they deploy automation in a way that preserves their own authorship and strong interpretative role-that is, for algorithms to assist editorial newswork in 'big data' projects instead of making use of its narrative affordances. Finally, factorial variance is worth bearing in mind when interpreting the results: European newsrooms are less centralised than their Anglo-American counterparts, resulting in a journalistic tradition less clearly separating between facts and comments-a distinction more clearly pronounced in American journalism. It is thus important to embed these findings in the associated media system and journalistic culture in which they are located to better understand how contextual factors play out in practice (Esser, 1999).

Overall, our findings run counter to-somewhat understandable-expectations that journalists would resist the rise of automated journalism; instead, our findings suggest that it can assist journalists in their daily news work and enable them to devote more attention to sophisticated workplace tasks that do still very much require the skills of human journalists. This also aligns with the results of a major report by the London School of Economics on Al in journalism, which found that "these technologies will augment the newsrooms and save valuable resources to be directed towards serious issues that require the attention of journalists" (Beckett, 2019, p. 53). Thus, while the 'replaceability' narrative comes close to a "dystopian moral panic" (Beckett, 2019, p. 53), the 'human touch' in journalism still comes at a premium-as, once again, confirmed by our interviewees, who discursively retained the core ideals of their professional ideology. This underlines "the centrality of human agency in technological innovation" (Milosavljević \& Vobič, 2019, p. 1113).

We suggest that future studies investigating the rise of algorithms in journalism would benefit from broadening and diversifying their theoretical and methodological scope in order to better cater to the transforming nature of the interplay between journalists and technology in much of contemporary journalism. While many of the prominent theoretical frameworks in journalism studies are rooted in the sociology discipline-such as Bourdieu's field theory (1984) - and based on qualitative interview data-as indeed this study does-moving forward, we suggest that in order to cater to the sociotechnical rise in journalism studies (Lewis \& Westlund, 2015), future studies may benefit from drawing even more on the emerging sub-discipline of human-machine communication (Lewis, Guzman, \& Schmidt, 2019) to fully grasp the quantitative turn (Coddington, 2015) in much of contemporary journalism, thus building our understanding of "not only 'who' does journalism, but also 'what' does 
journalism, and that 'what' includes technical artefacts and algorithms" (Diakopoulos, 2019, p. 36). We envisage a future hybrid state in which technological innovations gradually become embedded and interwoven in the fabric of the social arena the newsroom constitutes; as such, one of journalism's core ideals-autonomy-will have to be shared.

Amidst such industry upheaval, what is, indeed, certain is that "everything that can be automated will be automated," to pick up on the words of former Harvard Business School Professor Shoshana Zuboff (1988) again. Given its various affordances, the technology is likely here to stay. It is widely acknowledged that with further improvements in the readability of computer-generated articles, future uptakes of the technology are to be expected (Graefe, 2016). Equally, however, with the large number of articles automated journalism can produce in a relatively short space of time, concerns over possible information overload as a result of an increased quantity of available articles are rife. In the words of one journalist, "at a time when news itself is extremely important" $(\mathrm{J})$, he was looking forward to a time when readers would "orient themselves back to legacy organisations that help make sense of it all." The recent rise of digital subscriptions to The New York Times lend strong support to that view.

\section{Acknowledgments}

The research was supported by a research grant from the Australian Research Council [grant number DP160101211].

\section{Conflict of Interests}

The authors declare no conflict of interests.

\section{References}

Beckett, C. (2019). New powers, new responsibilities: A global survey of journalism and artificial intelligence. London School of Economics. Retrieved from https://blogs.Ise.ac.uk/polis/2019/11/18/newpowers-new-responsibilities

Bourdieu, P. (1984). Distinction: A social critique of the judgement of taste. London: Routledge.

Bucher, T. (2017). 'Machines don't have Instincts': Articulating the computational in journalism. New Media \& Society, 19(6), 918-933.

Carlson, M. (2015). The robotic reporter: Automated journalism and the redefinition of labour, compositional forms, and journalistic authority. Digital Journalism, 3(3), 416-431.

Carlson, M. (2018). Automating judgment? Algorithmic judgment, news knowledge, and journalistic professionalism. New Media \& Society, 20(5), 1755-1772.

Coddington, M. (2015). Clarifying journalism's quantitative turn: A typology for evaluating data journalism, computational journalism, and computer-assisted reporting. Digital Journalism, 3(3), 331-348.

Deuze, M. (2005). What is journalism? Professional identity and ideology of journalists reconsidered. Journalism, 6(4), 442-464.

Deuze, M. (2019). What journalism is (not). Social Media + Society. https://doi.org/10.1177/ 2056305119857202

Diakopoulos, N. (2019). Automating the news: How algorithms are rewriting the media. Cambridge, MA: Harvard University Press.

Dörr, K. (2016). Mapping the field of algorithmic journalism. Digital Journalism, 4(6), 700-722.

Esser, F. (1999). Tabloidization of news: A comparative analysis of Anglo-American and German press journalism. European Journal of Communication, 14(3), 291-324.

Gans, H. J. (1979). Deciding what's news: A study of CBS Evening News, NBC Nightly News, Newsweek and Time. New York, NY: Vintage Books.

Gillham, B. (2000). The research interview. London: Continuum.

Graefe, A. (2016). Guide to automated journalism. New York, NY: Tow Center for Digital Journalism. Retrieved from https://www.cjr.org/tow_center_reports/ guide_to_automated_journalism.php

Graefe, A., Haim, M., Haarmann, B., \& Brosius, H. B. (2016). Readers' perception of computer-generated news: Credibility, expertise, and readability. Journalism, 19(5), 595-610.

Gutierrez-Lopez, M., Missaoui, S., Makri, S., Porlezza, C., Cooper, G., \& Macfarlane, A. (2019). Journalists as design partners for Al. Paper presented at the CHI 2019 Conference, 4-9 May, Glasgow, UK.

Guzman, A. L., \& Lewis, S. C. (2020). Artificial intelligence and communication: A human-machine communication research agenda. New Media \& Society, 22(1), 70-86.

Haim, M., \& Graefe, A. (2017). Automated news: Better than expected? Digital Journalism, 5(8), 1044-1059.

Hanitzsch, T., \& Vos, T. P. (2017). Journalistic roles and the struggle over institutional identity: The discursive constitution of journalism. Communication Theory, 27, 115-135.

Hansen, M., Roca-Sales, M., Keegan, J., \& King, G. (2017). Artificial intelligence: Practice and implications for journalism. New York, NY: Tow Center for Digital Journalism \& Brown Institute for Media Innovation. Retrieved from https://academiccommons. columbia.edu/doi/10.7916/D8X92PRD

Hermida, A., \& Young, M. L. (2017). Finding the data unicorn. Digital Journalism, 5(2), 159-176.

Jones, R., \& Jones, B. (2019). Atomising the news: The (in)flexibility of structured journalism. Digital Journalism, 7(8), 1157-1179.

Jones, S. (2019). Untitled, No. 1: Human augmentics. In Z. Papacharissi (Ed.), A networked self and human augmentics, artificial intelligence, sentience (pp. 
201-205). New York, NY: Routledge.

Karlsen, J., \& Stavelin, E. (2014). Computational journalism in Norwegian newsrooms. Journalism Practice, 8(1), 34-48.

Lewis, S. C., Guzman, A. L., \& Schmidt, T. R. (2019). Automation, journalism, and human-machine communication: Rethinking roles and relationships of humans and machines in news. Digital Journalism, 7(4), 409-427.

Lewis, S. C., \& Westlund, O. (2015). Actors, actants, audiences, and activities in cross-media news work: A matrix and a research agenda. Digital Journalism, 3(1), 19-37.

Linden, C. G. (2017). Decades of automation in the newsroom: Why are there still so many jobs in journalism? Digital Journalism, 5(2), 123-140.

Lindlof, T. R., \& Taylor, B. (2010). Qualitative communication research methods ( $3 \mathrm{rd}$ ed.). Thousand Oaks, CA: Sage Publications.

Milosavljević, M., \& Vobič, I. (2019). Human still in the loop. Digital Journalism, 7(8), 1098-1116.

Montazeri, D., \& Kolbinger, O. (2017). Die Vermessung der Bundesliga [Rating the German premier league]. Spiegel online. Retrieved from https://www. spiegel.de/sport/fussball/bundesliga-spielernotenspix-und-spon11-die-vermessung-der-bundesliga-a1160253.html

Neuberger, C., \& Nuernbergk, C. (2010). Competition, complementary or integration? The relationship between professional and participatory media. Journalism Practice, 4(3), 319-332.

Retresco. (2017). Künstliche intelligenz: Tech company Retresco gewinnt World Summit Award der UN [Artificial intelligence: Tech company Retresco wins UN World Summit Award]. Retresco. Retrieved from https://www.retresco.de/kuenstliche-intelligenztech-company-retresco-gewinnt-world-summitaward-der-un

Shangyuan, W., Tandoc, Jr., E. C., \& Salmon, C. T. (2019). When journalism and automation intersect: Assessing the influence of the technological field on con- temporary newsrooms. Journalism Practice, 13(10), 1238-1254.

Stuttgarter Zeitung. (2018). Feinstaubradar ausgezeichnet: 'Big data im lokalen' [Award-winning fine dust radar: 'Big data' in a local setting]. Stuttgarter Zeitung. Retrieved from https://www.stuttgarternachrichten.de/inhalt.konrad-adenauer-preis-fuerfeinstaub-projekt-feinstaubradar-ausgezeichnetbig-data-im-lokalen.74dbd1bd-5c1c-432a-a4d7eda26ee1afa7.html

Thurman, N. (2019). Computational journalism. In K. Wahl-Jorgensen \& T. Hanitzsch (Eds.), The handbook of journalism studies (pp. 180-195). New York, NY: Routledge.

Thurman, N., Dörr, K., \& Kunert, J. (2017). When reporters get hands-on with robo-writing: Professionals consider automated journalism's capabilities and consequences. Digital Journalism, 5(10), 1240-1259.

Tuchman, G. (1978). Making news: A study in the construction of reality. New York, NY: The Free Press.

van Dalen, A. (2012). The algorithms behind the headlines: How machine-written news redefines the core skills of human journalists. Journalism Practice, 6(5), 648-658.

Wilkinson, D., \& Birmingham, P. (2003). Using research instruments: A guide for researchers. London: Routledge.

Wu, S., Tandoc, Jr., E. C., \& Salmon, C. T. (2019). When journalism and automation intersect: Assessing the influence of the technological field of contemporary newsrooms. Journalism Practice, 13(10), 1238-1254.

Young, M. L., \& Hermida, A. (2015). From Mr. and Mrs. outlier to central tendencies: Computational journalism and crime reporting at the Los Angeles Times. Digital Journalism, 3(3), 381-397.

Zeit Online. (2018). Straßennamen: Wie oft gibt es Ihre Straße? [Street names: How often does your street name exist?]. Zeit Online. Retrieved from https:// www.zeit.de/interactive/strassennamen

Zuboff, S. (1988). In the age of the smart machine: The future of work and power. New York, NY: Basic Books.

\section{About the Authors}

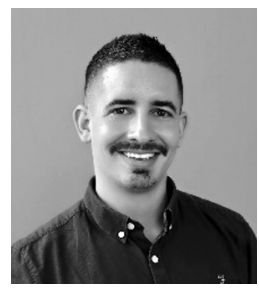

Aljosha Karim Schapals (PhD) is a Lecturer at the School of Communication with Queensland University of Technology. His research interests lie in the changes taking place in news production and consumption as a result of the internet. He also serves as Chief Investigator at the Digital Media Research Centre, where he is working on the 'Journalism beyond the Crisis' project funded by the Australian Research Council.

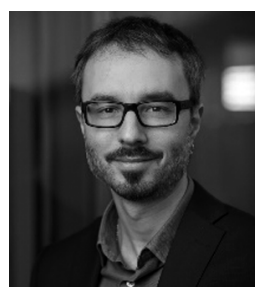

Colin Porlezza (PhD) is a Senior Lecturer at the Department of Journalism with City, University of London. His research focuses on the hybridization and datafication of digital journalism, as well as on media accountability and ethics. Currently, he is the Principal Investigator of the DMINR project, funded by the Google Digital News Initiative, which looks specifically into the design and the use of Al-based tools for journalistic investigations. 